\title{
Working Conditions of Retail Industry Workers in
}

\section{Hong Kong}

\author{
Fanny Y F Young (Corresponding author) \\ Dept. of Business Administration, Hong Kong Shue Yan University \\ 10 Wai Tsui Crescent, North Point, Hong Kong \\ Tel: 852-2570-7110Ｅ-mail: drfyoung@gmail.com
}

Received: December 10, 2018 Accepted: January 7, 2019 Published: January 17, 2019

doi:10.5296/jad.v5i2.14018 URL: https://doi.org/10.5296/jad.v5i2.14018

\begin{abstract}
This study investigated the relationship of working hour, work-life balance and mental health conditions in full-time retail industry workers in Hong Kong, an area without standard working hour legislation, in a follow up study during reduction in retail sales. Two questionnaire surveys were conducted, one in 2014 and the other one in 2015. Each survey comprised 100 retail industry workers in the same retail industry area in an anonymous basis. In 2014 the working hour was long (51.92 hours per week). During this reduction in retail sales there was a significant reduction in the originally long working hours (from 51.92 hours to 47.25 hours, $\mathrm{p}<0.0001)$, an increase in daily hours of personal or private activities $(3.06$ hours to 3.606 hours, not statistical significant), a significant increase in self-perceived work-life balance (from 3.76 to 4.51, $\mathrm{p}=0.0009$ ), a decrease in number of workers having problems due to disturbed work-life balance, and a significant decrease in the high mental health score (from 18.93 to $15.36, \mathrm{p}=0.0003$ ) indicating improvement in mental health conditions. The findings provide scientific evidence for policy making, the working hour in an area without standard working hour legislation could be long. Reduction in working hour resulted in an improvement in work-life balance and mental health conditions.
\end{abstract}

Keywords: Mental health conditions, retail industry, standard working hour, working hours, work-life balance 


\section{Introduction}

Work-life balance describes an individual's control over their work. A balance is achieved when an individual's right to a fulfilled life inside and outside paid work is accepted and respected as the norm, to the mutual benefit of the individual, business and society (Community Business, 2010). Long working hours result in a poor work-life balance, with ill effects such as an unwilling to work, a great likelihood of changing jobs, disharmony, lack of exercise, stress, poor diet, exhaustion, insomnia, depression and health problems (for example, cancer) (Afonso, Fonseca, \& Pires, 2017; Welford, 2008; Sparks et al., 1997). Mental health problems are among the most important factors affecting the burden of disease and disability worldwide. Five of the 10 global leading causes of disability are mental health problems. They are as relevant in low-income countries as they are in high-income countries, cutting across age, gender and social strata. There is increasing evidence that mental illness has a global effect (Harnois \& Gabriel, 2000). Long working hours negatively affect a worker's health through direct and indirect channels (Spurgeon, Harrington, \& Cooper, 1997). The stress of maintaining performance levels in the face of increasing fatigue over time and the increased chance of encountering other sources of workplace stress all negatively affect worker health. Therefore, the long working hour, poor work-life balance and poor mental health conditions are important social problems.

Investigating mental health conditions requires tools to detect and measure them. The General Health Questionnaire (GHQ), which was originally developed by Goldberg, has been widely used as a screening tool for individual risk of developing a psychiatric disorder (Goldberg \& Williams, 1988). The GHQ identifies the severity of psychological distress experienced by an individual within the past few weeks (Zulkefly \& Baharudin, 2010). It has been used extensively by researchers and has been found to be reliable and well-validated (Goldberg et al., 1997). Its psychometric properties have been studied in various countries (Werneke, Goldberg, Yalcin, \& Üstün, 2000) and with various populations, such as elderly people (Costa, Barreto, Uchoa, Firma, Lima-Costa, \& Prince, 2006) and urological patients (Quek, Low, Razack, \& Loh, 2001). The GHQ consists of 12 items, each assessing the severity of a mental problem over the past few weeks using a 4-point Likert-type scale (from 0 to 3). The GHQ or mental health score was used to generate a total score by summation ranging from 0 to 36 . A high mental health score indicated poor mental health conditions (Sánchez-López \& Dresch, 2008).

Several cross-sectional studies have shown an association between long working hours and mental ill health and fatigue symptoms (Virtanen et al., 2011). However, a longitudinal study demonstrating the bad effects of long working hour is lacking. It is highly important to investigate the relationship between long working hour, work-life balance and mental health conditions. To perform such a study it needs to select a place with long working hours and investigate the changes if the working hour is changed.

Long working hour can be a more severe problem in places with no legislation, and it can be much more serious in densely populated metropolitan cities. Hong Kong is such a place. It has no legislation performed on Standard Working Hours (Labour Department, 2019). Hong 
Kong full-time employees worked on average 49 hours per week, which was much higher than the maximum 40 hour work week defined by law in many countries (Chung, Pang, \& Tong, 2009; Labour Department, 2012). In 2015, the working hour in Hong Kong was increased to 50.1 hours per week, which was the highest among 71 cities in the World in a survey by a Switzerland banking group (UBS) (Li, 2016).

The next step was to select an industry in Hong Kong with long working hour.

Retail industry is one of the most essential sectors in Hong Kong's economy. Key services subsectors in Hong Kong include the import/export, wholesale and retail trades (accounted for 24.1 per cent of GDP in 2014) (Information Services Department, 2016). With this background, it is one of the industries with longest working hours with nearly 50 per cent of the full-time retail workers are working over 54 hours per week in Hong Kong (Labour Department, 2012). In addition, retail workers frequently need standing for long periods during the working hour (Watson, 2014) which may be more prone to have physical and mental stress. Therefore, retail industry is a good choice of long working hour industry for study.

Data from the Census and Statistics Department (CSD) showed the value of total retail sales in Hong Kong for the first eight months of 2015 decreased by 2.2 per cent compared with the same period in 2014. In August 2015, total retail sales, provisionally estimated at $\$ 37.9$ billion, decreased by 5.4 per cent compared with the same month in 2014. A government spokesman indicated in the CSD report that the weakening in retail sales was in part due to the slowdown in inbound tourism while the stock market gyrations of late might also have dented consumer sentiment (RetailTech Innovation, 2015). With this drop in business in retail industry, it is possible that the shops reduced staff working hours in order to minimise staffing and overhead cost. This provided a unique opportunity to investigate the effect of working hour reduction on work-life balance and mental health conditions. In 2014, in order to explore the working hour condition of retail industry in Hong Kong, the author performed a questionnaire survey on working hour, work-life balance and mental health conditions on the retail industry workers in a major retail industry area in Hong Kong, at that time the reduction in retail sales did not occurred. If the survey is performed again in 2015 after the reduction in retail sales and compare with the results with the 2014 study, it will be possible to detect the magnitude of reduction in working hour during this period and to detect the effects of this reduction on work-life balance and mental health conditions.

Research Aim: to investigate the effect of reduction of retail sales on working hours and the effects of reduction of working hour on work-life balance and mental health conditions in full-time retail industry workers in Hong Kong.

Working Hypotheses:

H1. Reduction in retail sales results in a reduction in working hours in retail industry workers.

$\mathrm{H} 2$. Reduction in working hours results in an improvement in work-life balance and mental health conditions in full-time retail industry workers. 


\section{Methodology}

The study was performed using two questionnaire surveys, one conducted in 2014 and the other one conducted in 2015. Each survey comprised 100 full-time retail industry workers in the same place, Causeway Bay, a major area of retail industry in Hong Kong. The retail industry workers in there were randomly selected and invited to answer the questionnaire in a voluntary and anonymous basis. Convenience sampling was used. Participants were asked individually face to face on each item and the responses were recorded on the questionnaire sheet in front of the participants. As there was no release of personal information possible, the participants were more likely to cooperate and give true information. Human research ethic approval was obtained through the Institution's Human Research Ethic Committee.

The questionnaire was a combination of the modified questionnaire used to study the work-life balance of the general Hong Kong population (Chung, Pang, \& Tong, 2009) which assessed working hours and work-life balance conditions and the modified 12-item GHQ (Goldberg \& Williams, 1988). The summation of response scores of this GHQ gave the mental health score which was an indication of the mental health conditions (Goldberg \& Williams, 1988). No personal identifiers were collected.

In more detail, the following areas are included in the questionnaire: working hour condition (item 1); hours spent on personal or private activities (item 2); self-perception of work-life balance condition (item 3); problem encountered because of disturbed work-life balance (Productivity and work quality has reduced dramatically due to long working hours, Prolonged fatigue level, sleepiness and extreme tiredness, I get physically sick easily and frequently due to heavy workload, I do not have any private time for recreation activities or sports at all, My work has affected my relationship with my friends, I don't have time staying with my partner and family, I feel stressed out, depressed and exhausted after work, Work pressure creates insomnia and poor diet, I become accident-prone, and Others, item 4); problems related to mental health condition (the conditions experienced in the past few weeks: Generally feeling unhappy, Thinking of self as worthless, Losing confidence, Feeling unhappy and depressed, Could not overcome difficulties, Incapable making decision, Cannot face up problems, Unable to concentrate, Do not enjoy normal activities, Do not play useful role in things, Constantly under strain, and Lost much sleep, item 5); gender (item 6); age (item 7); education attainment (item 8) and job experience in retail industry (item 9).

Sample size determination: It was targeted to obtain a sample size of 100 participants in each survey which was comparable to similar studies (Zaheer et. al., 2015).

The data were entered to an Excel (Microsoft Office v.2010, U.S.A.) file for data analyses. Unpaired $t$ tests were performed to detect differences between groups using Instat (v.3, U.S.A.).

\section{Results}

Two sets of 100 questionnaires were completed and the data were analysed and presented below: 


\section{Macrothink}

Journal of Asian Development

ISSN 2377-9594 2019, Vol. 5, No. 2

\subsection{Demographic Data}

In both years there were slightly more female workers in retail industry. In 2014 the percentage of male workers was 44 per cent and in 2015 that was 32 per cent.

They in general belonged to the younger age groups in 2014 with around one half (52 per cent) within the $20-24$ group. In 2015 with only one quarter ( 28 per cent) within this group; 48 per cent within the $25-34$ group and 24 per cent within the $35-54$ group (Table 1 ).

Table 1. Age distribution.

\begin{tabular}{crcc}
\hline Age range & Number, 2014 (\%) & $\mathrm{N}^{\dagger}=100$ & Number, 2015 (\%) \\
\hline $20-24$ & $52(52 \%)$ & $28(28 \%)$ \\
$25-29$ & $21(21 \%)$ & $33(33 \%)$ \\
$30-34$ & $17(17 \%)$ & $15(15 \%)$ \\
$35-39$ & $1(1 \%)$ & $6(6 \%)$ \\
$40-44$ & $2(2 \%)$ & $6(6 \%)$ \\
$45-49$ & $6(6 \%)$ & $3(3 \%)$ \\
$50-54$ & $1(1 \%)$ & $9(9 \%)$ \\
$55-59$ & $0(0 \%)$ & $0(0 \%)$ \\
over 60 & $0(0 \%)$ & $0(0 \%)$
\end{tabular}

${ }^{\dagger} \mathrm{N}=$ Total number of Subject.

The graph on age distribution (Figure 1) showed there were similar trends on age distribution in 2014 and 2015 with more retail industry workers in the youngest $(20-24)$ age group. There was less retail industry workers in the age range $20-24$ in 2015.

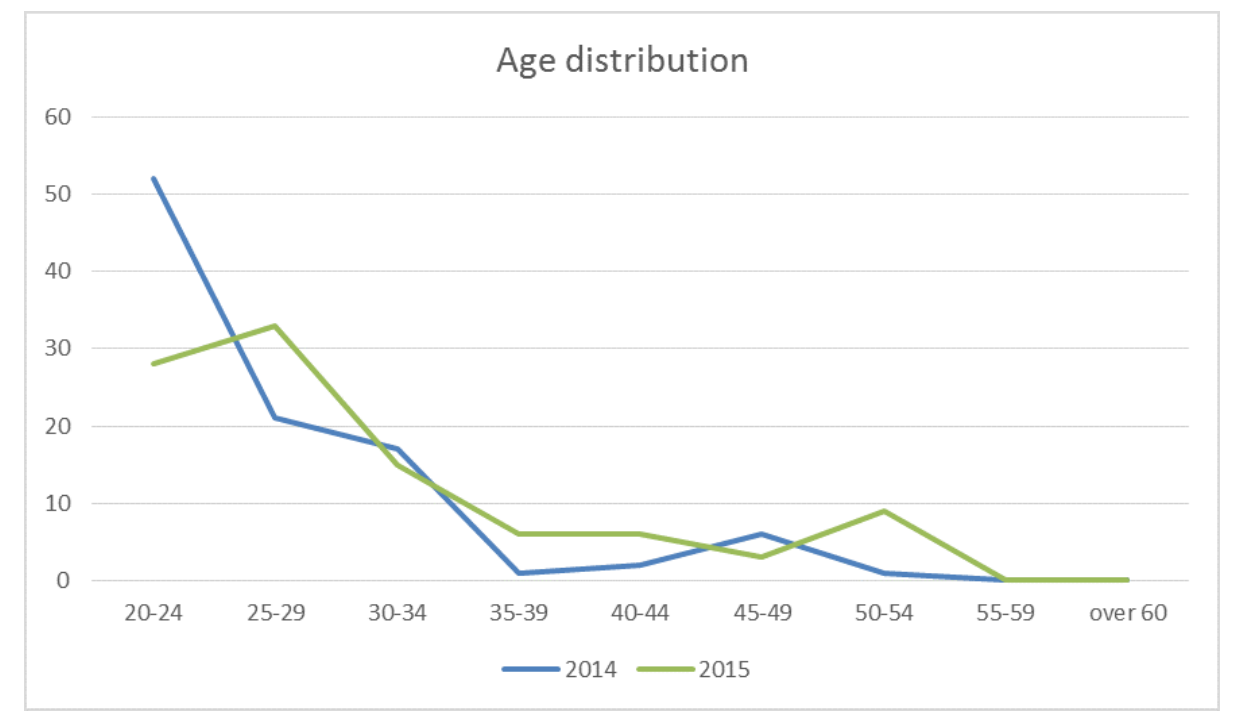

Figure 1. Age distribution 


\section{Macrothink}

\subsection{Education and Work Experience}

For education attainment, the distributions were similar in both 2014 and 2015, with more than half (61 per cent, 55 per cent respectively) subjects were having secondary school certificate level, around one third (31 per cent, 33 per cent respectively) subjects were having postsecondary school diploma level (Table 2).

Table 2. Education attainment distribution

\begin{tabular}{lllll}
\hline Education attainment & Number, 2014 (\%) & $\mathrm{N}^{\dagger}=100$ & Number, 2015 (\%) & $\mathrm{N}^{\dagger}=100$ \\
\hline Primary School & $2(2 \%)$ & $1(1 \%)$ & \\
Secondary School Certificate & $61(61 \%)$ & $55(55 \%)$ & \\
Postsecondary Diploma & $31(31 \%)$ & $33(33 \%)$ & \\
Bachelor Degree or above & $6(6 \%)$ & $11(11 \%)$ & \\
\hline
\end{tabular}

${ }^{\dagger} \mathrm{N}=$ Total number of Subject.

The graph on education attainment (Figure 2) showed there were similar trends on education attainment in 2014 and 2015 with more retail industry workers in the secondary school level.

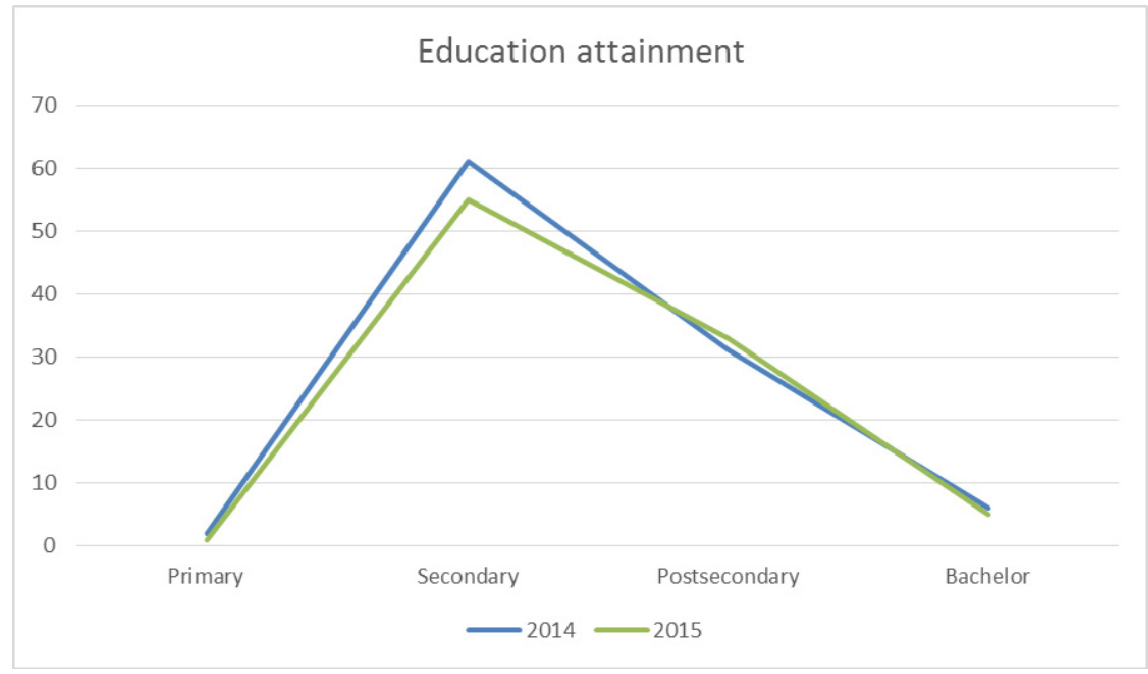

Figure 2. Education attainment distribution

For working experience in retail industry, 67 per cent were having working experience less than 4 years in 2014 and 49 per cent were having this experience in 2015. Therefore the percentage on less experienced workers decreased from 2014 to 2015 (Table 3). 
Table 3. Distribution of Working Experience in Retailing Industry.

\begin{tabular}{|c|c|c|c|}
\hline Working Experience & Number, $2014(\%)$ & $\mathrm{N}^{\dagger}=100$ & $\begin{array}{c}\text { Number, } 2015(\%) \\
N^{*}=100\end{array}$ \\
\hline Less than 2 years & $27(27 \%)$ & & $26(26 \%)$ \\
\hline 2 years to 4 years & $40(40 \%)$ & & $23(23 \%)$ \\
\hline 4 years to 6 years & $16(16 \%)$ & & $26(26 \%)$ \\
\hline 6 years to 8 years & $13(13 \%)$ & & $5(5 \%)$ \\
\hline More than 8 years & $4(4 \%)$ & & $20(20 \%)$ \\
\hline
\end{tabular}

${ }^{\dagger} \mathrm{N}=$ Total number of Subject.

The graph on working experience (Figure 3) showed that in 2014 in general there was more workers with less experience than that in 2015.

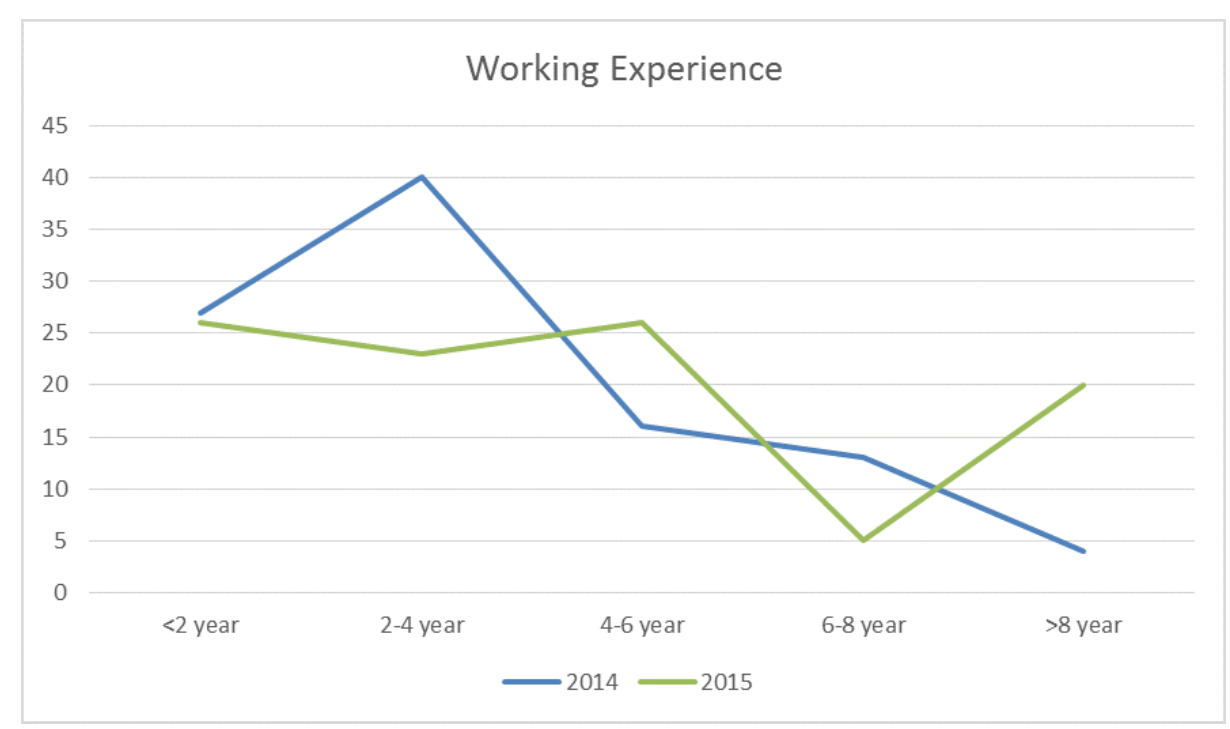

Figure 3. Distribution of Working Experience

\subsection{Working Hour}

The average working hour per week of workers in 2014 was 51.92 hours $(\mathrm{SD}=7.291)$ and that in 2015 was 47.25 hours $(S D=6.168)$. The difference was significant $(\mathrm{p}<0.0001$, Mann-Whitney test). In 2014 more than half (53 per cent) workers worked more than 51 hours and in 2015 this percentage was dropped to $19 \%$ (Table 4). 


\section{Macrothink}

Table 4. Distribution of the 'work hour'

\begin{tabular}{|c|c|c|}
\hline Work hour per week & Number, $2014(\%) \quad \mathrm{N}^{\dagger}=100$ & $\begin{array}{l}\text { Number, } 2015(\%) \quad \mathrm{N}^{\dagger}=100 \\
\end{array}$ \\
\hline$<30$ & $2(2 \%)$ & $0(0 \%)$ \\
\hline $31-40$ & $21(21 \%)$ & $14(14 \%)$ \\
\hline $41-50$ & $43(43 \%)$ & $67(67 \%)$ \\
\hline $51-60$ & $48(48 \%)$ & $18(18 \%)$ \\
\hline $61-70$ & $4(4 \%)$ & $1(1 \%)$ \\
\hline $71-80$ & $1(1 \%)$ & $0(0 \%)$ \\
\hline$>80$ & $0(0 \%)$ & $0(0 \%)$ \\
\hline
\end{tabular}

${ }^{\dagger} \mathrm{N}=$ Total number of Subjects.

The graph on working hour distribution (Figure 4) showed that in 2015 the peak of the working hour distribution curve shifted to the left side of that of 2014, indicating that the majority of retail industry workers in 2015 worked with less working hour than that of 2014 .

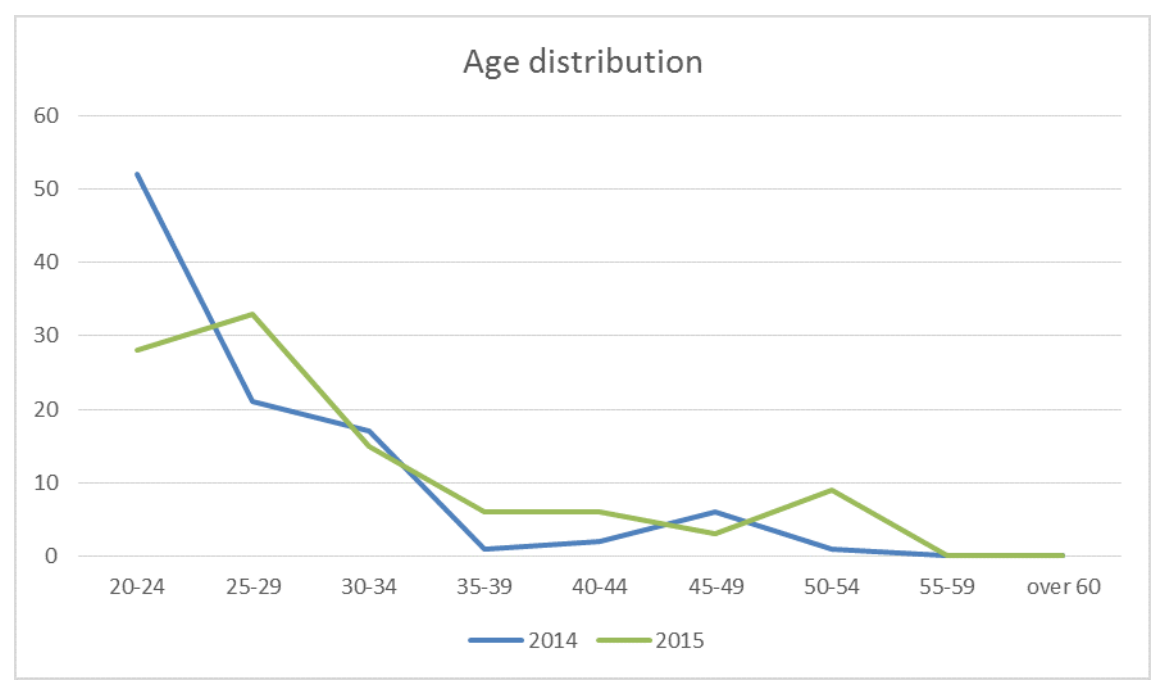

Figure 4. Distribution of the 'work hour'

\subsection{Personal or Private Activities}

The average hours of personal or private activities per day in 2014 was 3.06 hours $(\mathrm{SD}=0.77)$ and that in 2015 was 3.606 hours $(S D=2.159)$. The difference was not significant $(p=0.4$, Mann-Whitney test). In 2014 around half (47 per cent) workers had $3-4$ hours of personal or private activities per day and in 2015 this percentage was dropped to 15 per cent. Whereas the percentage of workers having either very few ( $<2$ hours) or very big ( $>5$ hours) amount of hours of personal or private activities per day increases to around 30 per cent. 
Table 5. Distribution of hours of personal or private activities per day

\begin{tabular}{|c|c|c|c|c|}
\hline $\begin{array}{l}\text { Hours of personal or private activities per } \\
\text { day }\end{array}$ & Number, 2014 (\%) & $\mathrm{N}^{\dagger}=100$ & Number, 2015 (\%) & $\mathrm{N}^{\dagger}=100$ \\
\hline$<2$ & $13(13 \%)$ & & $31(31 \%)$ & \\
\hline$>2-3$ & $27(27 \%)$ & & $11(11 \%)$ & \\
\hline$>3-4$ & $47(47 \%)$ & & $15(15 \%)$ & \\
\hline$>4-5$ & $13(13 \%)$ & & $10(10 \%)$ & \\
\hline$>5$ & $0(0 \%)$ & & $33(33 \%)$ & \\
\hline
\end{tabular}

${ }^{\dagger} \mathrm{N}=$ Total number of Subject.

The graph on hours of personal or private activities per day (Figure 5) showed that in 2015 there were more workers having either very few or very big amount of hours of personal or private activities per day than that in 2014 .

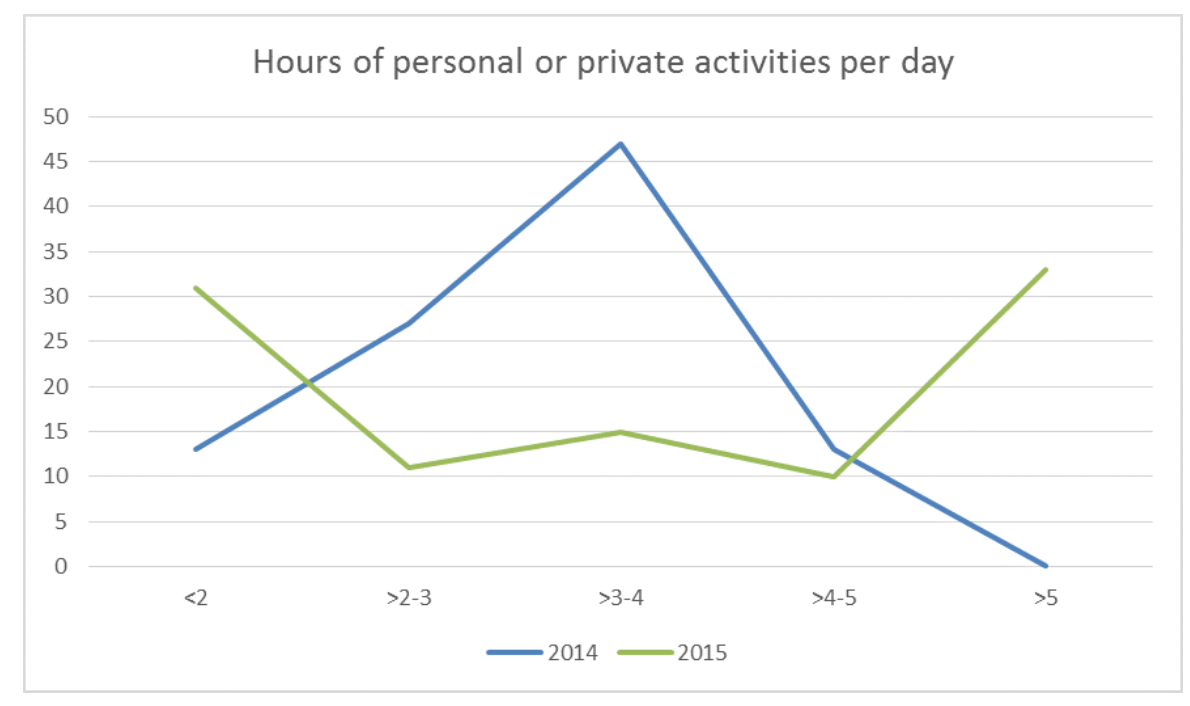

Figure 5. Distribution of hours of personal or private activities per day

\subsection{Self-Perceived Work-Life Balance}

The average degree of achieved work-life balance in 2014 was $3.76(\mathrm{SD}=1.327)$ and that in 2015 was $4.51(\mathrm{SD}=1.599)$. The difference was significant $(\mathrm{p}=0.0009$, Mann-Whitney test). In 2014 less than one third ( 29 per cent) workers had the degree of work-life balance above 5 and in 2015 this percentage was increased to 49 per cent. This indicated the percentage of worker having higher degree of work-life balance increased (Table 6). 


\section{Macrothink}

Table 6. Distribution of degree of achieved work-life balance.

\begin{tabular}{llll}
\hline Degree of achieved work-life balance & Number, 2014 (\%) $\mathrm{N}^{\dagger}=100$ & $\begin{array}{l}\text { Number, } \\
\mathrm{N}^{\dagger}=100\end{array}$ & 2015 \\
\hline 0 & $0(0 \%)$ & $0(0 \%)$ & \\
$1-2$ & $17(17 \%)$ & $8(8 \%)$ & \\
$3-4$ & $54(54 \%)$ & $43(43 \%)$ & \\
$5-6$ & $27(27 \%)$ & $38(38 \%)$ & \\
$7-8$ & $2(2 \%)$ & $11(11 \%)$ & \\
$9-10$ & $0(0 \%)$ & $0(0 \%)$ & \\
\hline
\end{tabular}

${ }^{\dagger} \mathrm{N}=$ Total number of Subject.

The graph on the degree of achieved work-life balance (Figure 6) showed that in 2015 the peak of the curve was shifted to the right side compared to that in 2014, indicating that the majority of workers has increased degree of achieved work-life balance.

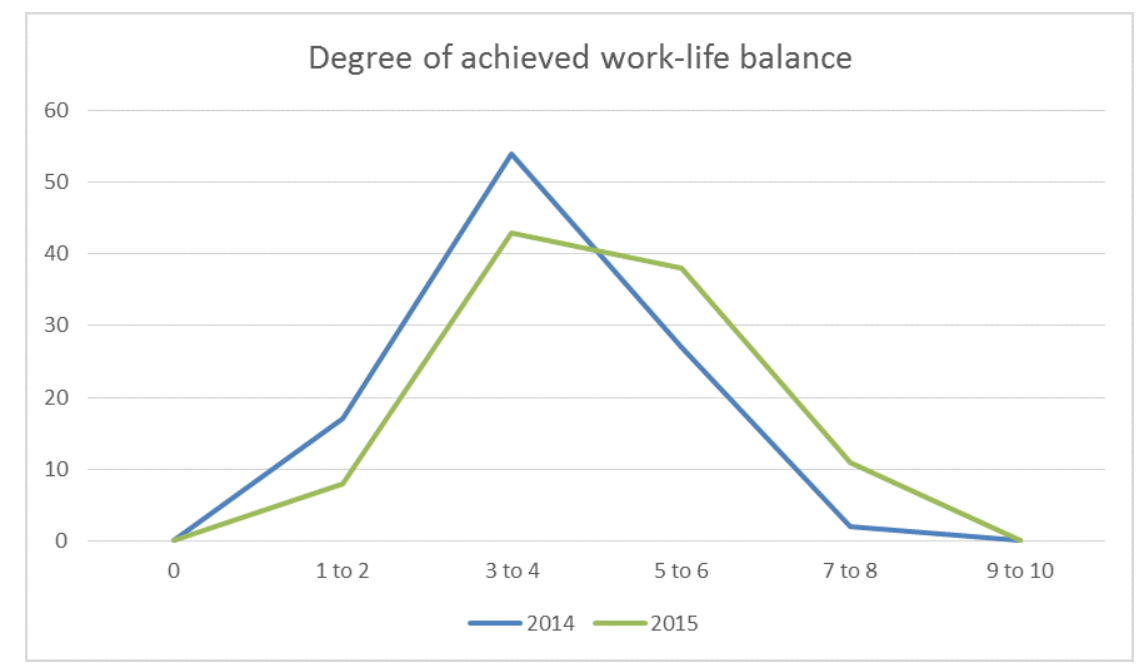

Figure 6. Distribution of degree of achieved work-life balance.

\subsection{Problems due to Disturbed Work-Life Balance}

In both 2014 and 2015, there were more workers (76 per cent, 74 per cent respectively) reported prolonged fatigue level, sleepiness and extreme tiredness, this was the most common problem due to disturbed work-life balance (Table 7). 
Table 7. Distribution of Problems due to a disturbed work-life balance.

Type of problems:

$\begin{array}{ll}\text { Number, } 2014(\%) & \text { Number, } 2015(\%) \\ \mathrm{N}^{\dagger}=100 & \mathrm{~N}^{\dagger}=100\end{array}$

Productivity and/or work quality has reduced 63(63\%) $55(55 \%)$

dramatically due to long working hours.

Prolonged fatigue level, sleepiness and/or extreme 76(76\%)

$74(74 \%)$ tiredness.

I get physically sick easily and/or frequently due to $34(34 \%)$

$34(34 \%)$

heavy workload.

I do not have any private time for recreation activities $42(42 \%)$

$34(34 \%)$

or sports at all.

My work has adversely affected my relationship with my friends.

$64(64 \%)$

$25(25 \%)$

I don't have time staying with my partner and/or $64(64 \%)$

$39(39 \%)$

family.

I feel stressed out, depressed and/or exhausted after $51(51 \%)$

$47(47 \%)$

work.

Work pressure creates insomnia and/or poor diet

$67(67 \%)$

$25(25 \%)$

I become accident-prone

$38(38 \%)$

$9(9 \%)$

${ }^{\dagger} \mathrm{N}=$ Total number of Subject.

The graph on problems due to disturbed work-life balance (Figure 7) showed that in 2015 the curve had a level lower than that in 2014, indicating that in general the number of workers having problem was decreased.

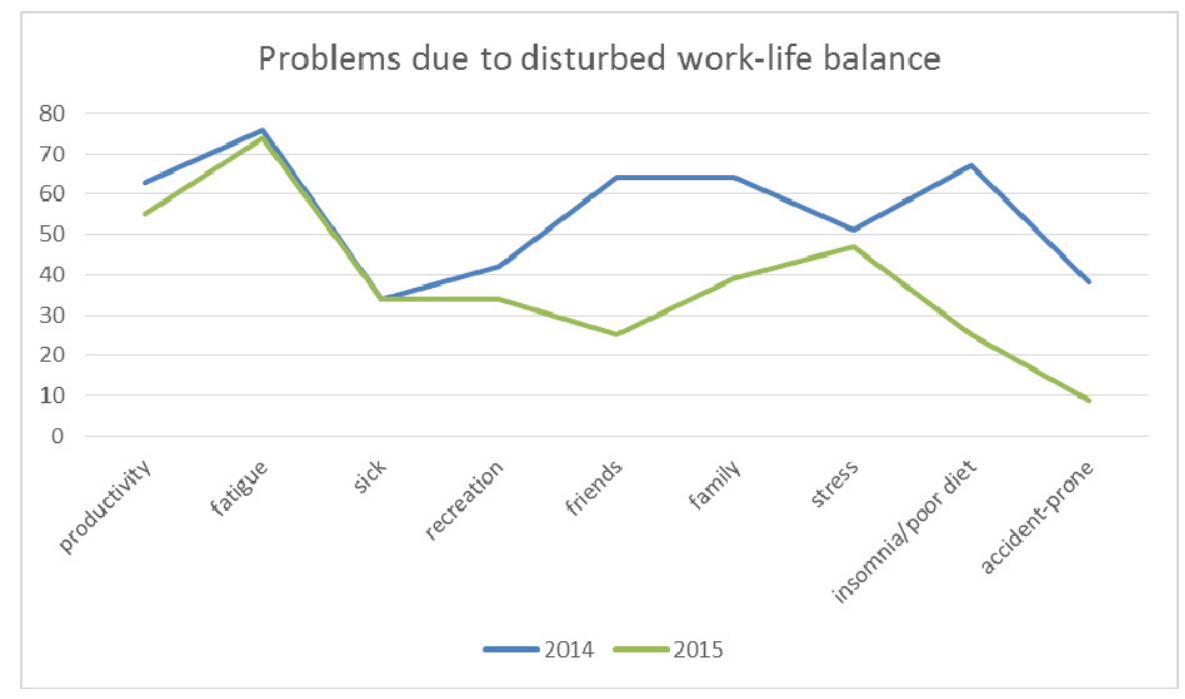

Figure 7. Distribution of Problems due to a disturbed work-life balance 


\section{Macrothink}

Journal of Asian Development

ISSN 2377-9594 2019, Vol. 5, No. 2

\subsection{Mental Health Conditions}

The mean mental health score in 2014 was $18.93(\mathrm{SD}=6.241)$ and that in 2015 was 15.36 $(\mathrm{SD}=7.705)$. The difference was significant ( $\mathrm{p}=0.0003$, Mann-Whitney test). In 201414 per cent workers had the mean mental health score below 12 and in 2015 this percentage was increased to 40 per cent. This indicated the percentage of worker having low mental health score or improved mental health conditions increased (Table 8).

Table 8. Distribution of Mental health Conditions

\begin{tabular}{lll}
\hline Summation of scores: & $\begin{array}{l}\text { Number, 2014 (\%) } \\
\mathrm{N}^{\dagger}=100\end{array}$ & $\begin{array}{l}\text { Number, } 2015(\%) \\
\mathrm{N}^{\dagger}=100\end{array}$ \\
\hline $0-6$ & $5(5 \%)$ & $15(15 \%)$ \\
$7-12$ & $9(9 \%)$ & $25(25 \%)$ \\
$13-18$ & $27(27 \%)$ & $25(25 \%)$ \\
$19-24$ & $43(43 \%)$ & $21(21 \%)$ \\
$25-30$ & $14(14 \%)$ & $11(11 \%)$ \\
$31-36$ & $2(2 \%)$ & $3(3 \%)$ \\
\hline
\end{tabular}

${ }^{\dagger} \mathrm{N}=$ Total number of Subject.

The graph on the mental health score (Figure 8) showed that in 2015 the peak of the curve was shifted to the left side compared to that in 2014, indicating that the majority of workers has decreased mental health scores or improved mental health conditions.

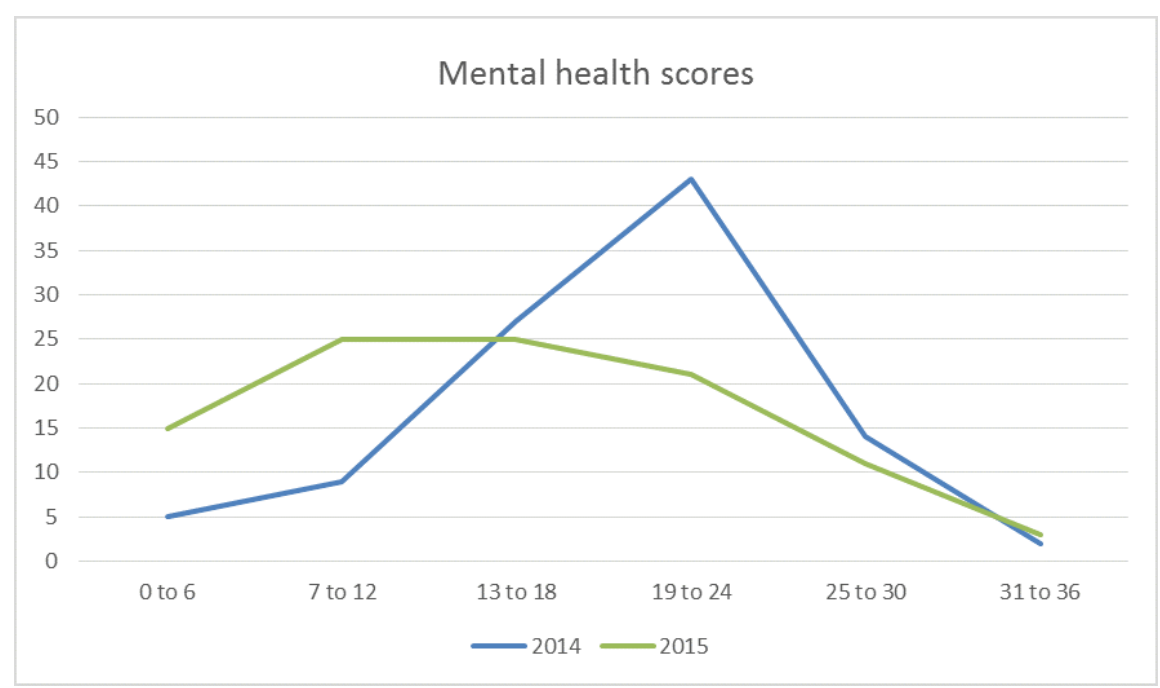

Figure 8. Distribution of Mental health Conditions 


\section{Discussion}

This is the first follow up study looking at the changes in working hours, work-life balance and mental health conditions in retail industry in Hong Kong during a period of rapid dropping in retail sales, selected Hong Kong as an example of a metropolitan city without standard working hour legislation and selected retailing industry was an industry with long working hour. Ideally an experimental study design should be employed. Practically it would be extremely difficult to change the working hours of the workers even in one company. The economic changes in Hong Kong allowed a valuable opportunity to perform a longitudinal study, therefore this study attempted to capture the best study timing as the working hour was likely to decrease with the reduction in retail sales. It would be ideal to follow up the same group of subjects in the second questionnaire survey, however, as the study is anonymous, it would be impossible to identify the same group again. The reason of being anonymous was to prevent leaking of personal information and to allow the subjects to be more willing to participate and to disclose the true information as there would be no chance for their employers to take any actions against them.

The result in age distribution showed that there was rapid drop of retail industry workers in the youngest age group, from $52 \%$ to $28 \%$ (Table 1, Figure 1). It might be because less young people were joining the retail industry after they graduate, seeing the dropping in retail sales and might also because less vacancies were available because of the dropping in business. There was more experienced workers working in retail industry during drop in retail sales (Table 3, Figure 3), this might be because the more experienced workers were more able to stay behind in this business during this period. The mean working hour per week was 51.92 $(\mathrm{SD}=7.921)$ in 2014 and $47.25(\mathrm{SD}=6.168)$ in 2015 , showing there was a significant reduction of working hour ( $p<0.01$, Mann-Whitney test) during this period of dropping in retail sales. The table and graph distribution of the working hour (Table 4, Figure 4) also showed similar effect. This agreed with our postulation that the drop in retail sales would lead to a reduction of work hour. This also showed in 2014, the work-hour in retail industry workers in Hong Kong, an area without standard working hour, was very high (51.92 hour/week) when compared with other countries with standard working hour (40 hour/week) in other countries (Ghosheh, 2013). In 2015, the working hour was also high (47.25 hour/week) even after reduction. The change of the distribution of hours of personal or private activities per day between 2014 and 2015 were unexpected and difficult to explain (Table 5, Figure 5). There were increase in people with more $(>5)$ hours of personal or private activities per day, there were also increase in people with less $(<2)$ hours of personal or private activities. Further research will be needed to investigate this change. The degree of achieved work-life balance was significantly improved ( $\mathrm{p}=0.0009$, Mann-Whitney test) with the mean degree in 2014 was $3.76(\mathrm{SD}=1.327)$ and that in 2015 was $4.51(\mathrm{SD}=1.599)$. The table and graph (table 6, figure 6) of degree of achieved work-life balance showed similar effect. Therefore, this result supported with our hypothesis that reduction in working hours caused an improvement in work-life balance. For the problems due to a disturbed work-life balance, which in both years most workers $(76 \%, 74 \%$ respectively, Table 7 , Figure 7$)$ has the problem of prolonged fatigue level, sleepiness and/or extreme tiredness, the number of 
workers having problems was less in 2015 where the working hour was reduced. This indirectly supported the hypothesis that reduction in working hours caused an improvement in work-life balance. For the mental health conditions, with the reduction in working hour, the mean mental health score significantly reduced from 18.93 to 15.36 . This result was also illustrated in Table 8 and Figure 8. As a reduction in mean mental health score was related to an improvement in mental health conditions, this supported the hypothesis that reduction in working hours results in an improvement in mental health conditions. Further studies should be performed to follow up the working hour, work-life balance and mental health conditions of these retail industry workers in Hong Kong with reference to the retail sales condition at regular intervals. It is also important to look at these conditions in other industries and in different places longitudinally to see whether the relationships identified in this study are industry, area and population related.

This is also the first study to investigate the mental health conditions on retail industry workers in Hong Kong. This data can be used as a reference to compare different industries, different working hours, different areas, different populations and different environmental, socioeconomic and political conditions. This can be highly useful especially in the field of working hours and work-life balance research. As there was no similar study on retail industry workers the result cannot be directly compared. However if we compare this with a population study, the mean mental health score of Spanish general population (1001 aged 25-65) which was 8.52 ( $\mathrm{SD}=5.38$ ) (Sánchez-López and Dresch, 2008), it showed the mental health conditions of the Hong Kong retail industry workers was much poorer than those of the other populations even with the improvement in the mean mental health score after reduction in working hour.

\section{Conclusion}

Results of this study showed that in Hong Kong, an area without standard working hour legislation, the working hour was long resulting in poor work-life balance and poor mental health condition. Reduction in working hour resulted in an improvement in work-life balance and mental health conditions. The limitations of study includes the small sample size and the inability to follow up the same subjects in the follow up questionnaire. This is the scientific evidence which should be considered during policy making.

\section{Acknowledgement}

This study was supported by Hong Kong Shue Yan University's RSDC research grant (RSDG No. 14001A).

\section{References}

Afonso, P., Fonseca, M., \& Pires, J. F. (2017). Impact of working hours on sleep and mental health. Occupational Medicine. 67. 377-382. http://dx.doi.org/10.1093/occmed/kqx054

Chung, T. Y. R, Pang, K. L. K., \& Tong, Y. W. J. (2009). Work Life Balance Survey of the Hong Kong Working Population 2009. Hong Kong: The University of Hong Kong. Retrieved December 
http://www.communitybusiness.org/images/cb/publications/2009/WLB09_HKU.pdf

Community Business (2010). Definition of Work-life Balance. Retrieved November 16, 2017, from http://www.communitybusiness.org/focus_areas/WLB.htm\#1

Costa, E., Barreto, S. M., Uchoa, E., Firma, J. O. A., Lima-Costa, M. F., \& Prince, M. (2006). Is the GDS-30 better than the GHQ-12 for screening depression in elderly people in the community? The Bambui Health Aging Study (BHAS). International Psychogeriatrics, 18, 493-503. http://doi.org/10.1017/S1041610205002954

Ghosheh, N. (2013). Working conditions laws report 2012. A global review. Geneva: International Labour Organization.

Goldberg, D., \& Williams, P. (1988). A user's guide to the General Health Questionnaire. Windsor: NFER-Nelson.

Goldberg, D., Gater, R., Sartorius, N., Ustun, T., Piccinelli, M., Gureje, O., \& Rutter, M. (1997). The validity of two version of the GHQ in the WHO study of mental illness in general health care. Psychology Medicine, 27, 191-197. http://doi.org/10.1017/S0033291796004242

Harnois, G., \& Gabriel, P. (2000). Mental health and work: Impact, issues and good practices. Geneva: World Health Organization.

Information Services Department. (2016). HONG KONG: THE FACTS. Trade and Industry. Hong Kong: Hong Kong Special Administrative Region Government.

Labour Department. (2012). Report of the Policy Study in Standard Working Hours. Hong Kong: Government Logistics Department.

Labour Department. (2019). WORKING HOURS POLICY. Retrieved January 2, 2019, from https://www.labour.gov.hk/eng/plan/whp.htm

Li, S. (2016). HK has longest working week of 71 cities. ChinaDaily Asia. May 25. Retrieved January 2, 2019, from https://www.chinadailyasia.com/hknews/2016-05/25/content_15439024.html

Quek, K. F., Low, W. Y., Razack, A. H., \& Loh, C. S. (2001). Reliability and validity of the General Health Questionnaire (GHQ-12) among urological patients: A Malaysian study. $\begin{array}{llll}\text { Psychiatry and Clinical 5eurosciences, } & 55,\end{array}$ http://doi.org/10.1046/j.1440-1819.2001.00897.x

RetailTech Innovation (2015). Is Hong Kong retail really shifting from high-end to mid-market? $\quad$ Retrieved June $7, \quad 2017$, from http://www.enterpriseinnovation.net/article/hong-kong-retail-really-shifting-high-end-mid-ma rket-628716090 ().

Sánchez-López, M., \& Dresch, V. (2008). The 12-Item General Health Questionnaire (GHQ-12): Reliability, external validity and factor structure in the Spanish population. Psicothema, 4(20). 839-843. 


\section{Macrothink

Sparks, K., Cooper, C., Fried, Y., \& Shirom, A. (1997). The effects of hours of work on health: A meta-analytic review. Journal of Occupational and Organizational Psychology, 70, 391-408. http://dx.doi.org/10.1111/j.2044-8325.1997.tb00656.x

Spurgeon, A., Harrington, J., \& Cooper, C. (1997). Health and safety problems associated with long working hours: a review of the current position. Occupational Environmental Medicine, 6(54). 367-375.

Virtanen, M., Ferrie, J. E., Singh-Manoux, A., Shipley, M. J., Stansfeld, S. A., Marmot, M. G., \& Kivimäki, M. (2011). Long working hours and symptoms of anxiety and depression: A 5-year follow-up of the Whitehall II study. Psychological Medicine, 41(12). 2485-2494. http://doi.org/10.1017/S0033291711000171

Watson, K. (2014). Standing for long periods. Retrieved August 30, 2017, from http://www.safeworkers.co.uk/standing-for-long-periods.html

Welford, R. (2008). Work-life balance in Hong Kong: Survey Result. Hong Kong: The University of Hong Kong. Retrieved October 1, 2016, from http://www.ethicsworld.org/ethicsandemployees/PDF\%20links/Hong\%20Kong\%20WLB.pdf

Werneke, U., Goldberg, U. P., Yalcin, I., \& Üstün, B. T. (2000). The stability of the factor structure of the General Health Questionnaire. Psychological Medicine, 30, 823-829. http://dx.doi.org/10.1017/S0033291799002287

Zaheer, A., Islam, J. U., \& Darakhshan, N. (2015). Occupational Stress and Work-Life Balance: A Study of Female Faculties of Central Universities in Delhi, India. Journal of Human Resource Management, 4(1), 1-5. http://doi.org/10.11648/j.jhrm.20160401.11

Zulkefly, N., \& Baharudin, R. (2010). Using the 12-item General Health Questionnaire (GHQ-12) to assess the Psychological Health of Malaysian College students. Global Journal of Health Science, 1(2), 73-80. http://doi.org/10.5539/gjhs.v2n1p73

\section{Copyright Disclaimer}

Copyright for this article is retained by the author(s), with first publication rights granted to the journal.

This is an open-access article distributed under the terms and conditions of the Creative Commons Attribution license (http://creativecommons.org/licenses/by/4.0/). 